\title{
Mesoporous Materials toward Nanofabricator and Nanoreactor
}

\author{
Ichizo YagI, ${ }^{\text {a, } *}$ Akari Hayashi, ${ }^{a}$ Ken'ichi Kimijima, ${ }^{a}$ Hideo Notsu, ${ }^{\text {a }}$ \\ Narumi OHTA, and Akira YAMAGUCHI ${ }^{\mathrm{b}}$
}

\author{
${ }^{a}$ FC-Cubic, National Institute of Advanced Industrial Science and Technology (AIST) (2-3-26 Aomi, Koto-ku, Tokyo \\ 135-0064, Japan) \\ ${ }^{\text {b} D e p a r t m e n t ~ o f ~ C h e m i s t r y, ~ G r a d u a t e ~ S c h o o l ~ o f ~ S c i e n c e, ~ T o h o k u ~ U n i v e r s i t y ~(A o b a-k u, ~ S e n d a i ~ 980-8578, ~ J a p a n) ~}$
}

Received September 29, 2009 ; Accepted October 15, 2009

\begin{abstract}
Construction of nanomaterials has been developed from both top-down and bottom-up approaches. In these approaches, surfactant-templated mesoporous materials are promising because of their tunability, uniformity and reproducibility in both the size and shape of produced mesopores. Mesoporous silica materials have been widely and deeply investigated in the early stage, basing on the sol-gel chemistry of silicate. Although insulating mesoporous silica cannot be directly applicable to electrode materials, the mesoporous silica films and their hybrid films are recently applied as hard templates and electrodeposition of metals inside the mesopores realizes the formation of metal nanowire assembly, which has parallel orientation to the electrode surface. Furthermore, the mesoporous silica film with perpendicularly oriented mesochannels are prepared and used as hard-template, resulting in the fabrication of metal nanowire assembly standing on the electrode surface. On the other hand, conductive materials are recently fabricated as mesoporous structure by the surfactant-template method. Mesoporous carbon becomes the most conventional mesoporous conductive material and has been investigated as the electrode material mainly applicable to energy conversion. By introducing catalyst particles and ionomers inside mesochannels, triple phase boundary can be constructed and the application toward cathode electrode in the polymer electrolyte fuel cell (PEFC) has been investigated.
\end{abstract}

Key Words : Mesoporous Materials, Nanofabricator, Nanoreactor Array, Electrocatalysts

\section{Introduction}

Mesoporous materials have appeared over the last two decades ${ }^{1-3)}$ and their tunablity in both the size and the shape has been attractive in various fields dealing with nano- and meso-scale materials. Nevertheless, synthetic methods, structural analyses of mesoporous materials and exploration of phenomena occurring in mesopores have been still important from the fundamental viewpoint, and the practical simplicity to prepare ordered porous materials with controllable structures can be directly applicable to the fields such as adsorption, separation, drug delivery, sensors, photonics and nanodevices. Obtained surfactant-templated mesoporous materials have provided not only a series of novel materials that possess uniform and tunable $(1.5-15 \mathrm{~nm})$ pore sizes, highly ordered nanochannels, and large surface areas $(\sim 1500$ $\mathrm{m}^{2} \mathrm{~g}^{-1}$ ), but also a large variety of mesoporous materials with different meso-structures (space groups of twodimensional (2D) hexagonal: p6mm, three-dimensional (3D) hexagonal: $P 6_{3} / m m c$, 3D cubic: $P m \overline{3} m, P m \overline{3} n, F d \overline{3} m$, $F m \overline{3} m$, $\operatorname{Im} \overline{3} m$, etc.). Although the compositions of these materials, expanded to metal oxides, ${ }^{2,4)}$ metals, ${ }^{5-7)}$ polymers, ${ }^{8)}$ carbon, ${ }^{9,10}$ carbon nitride, ${ }^{11)}$ and their hybrids ${ }^{12-15)}$ are still increasing, mesoporous silica have been the most actively investigated, owing to the elaboration in sol-gel chemistry of silicate.

Surfactant-templated mesoporous silica materials ${ }^{16,17}$ have been expected as a stable nanofabricator (hard template) to synthesize a metal nanowire assembly due to their well-defined mesochannel structure. In mesoporous silica powders, such as SBA-15, ${ }^{18)} \mathrm{MCM}-41,{ }^{19)}$ and HMM- $1,{ }^{20)}$ growth of metal nanowires inside the silicamesochannels have been performed by chemical or photoreduction of metal precursors infiltrated into the silicamesochannels. However, the as-synthesized metal nanowires sometimes lack macroscopic continuity and periodicity. Collection and subsequent immobilization of metal nanowires on a substrate surface are sometimes necessary for an application of metal nanowires. Accordingly, a template-electrodeposition using a mesoporous silica film on a plane electrode has been attempted to fabricate hierarchical and/or well-ordered metal nanowire assembly. ${ }^{20,21)}$ In the template-electrodeposition, an electrochemical growth of metal nanowire assembly is carried out within a mesoporous silica film as a nanofabricator. The considerable advantages of this fabrication approach are a continual growth of metal nanowires from the electrode surface, large-scale fabrication of metal nanowire assembly, and simple usage of the metal nanowire assembly after removal of the template by a chemical treatment. ${ }^{21)}$ The pore structure of mesoporous silica film determines the final meso-structure of metal nanowire assembly. Details will be described in Chapter 2 .

The hard template methods including template-electrodeposition seem ideal to prepare nanomaterial array with large area and well reproducibility. However, result- 
ing nanomaterials using a hard template is ordered arrays of nanorods with reverse structures to parent mesoporous structures of silica. The produced pores are not well tunable and are ranging normally 2-5 nm even if a hard template with relatively large pore sizes reaching $\sim 10 \mathrm{~nm}$ is used, since the mesopores' wall thickness in the mesoporous silica template are not very much controllable. Doubly transcription can realize the reconstruction of the nanostructure of the original template by a different composition, but the complication in the synthesis processes and the deterioration of the uniformity in the size and orderliness of the resulting pores cannot be denied. Thus, the direct synthesis of surfactant-templated mesoporous materials should be desired, if the welldefined mesochannel structure is utilized as electrochemical reaction spaces. We have particularly synthesized mesoporous carbon (MC) through self-organization of carbon precursors and a surfactant followed by carbonization. ${ }^{22,23)}$ The resulted pore size is $7-8 \mathrm{~nm}$, and ordered pore structure spreads out three dimensionally. Both Pt catalysts and perfluorosulfoic acid polymers (PFSAs) were successfully deposited inside the pores in order to build up a triple phase boundary within such nano-space to construct a novel type of electrocatalyst applicable to the polymer electrolyte fuel cell (PEFC). ${ }^{24-26)}$ Several Pt deposited MC (Pt/MC) catalysts were synthesized just changing by $\mathrm{Pt}$ precursors and were fully characterized. Details of oxygen reduction reaction (ORR) reactivity of those $\mathrm{Pt} / \mathrm{MC}$ catalysts and distinctive oxygen transfer and storage system occurring inside the pores are discussed in Chapter 3.

\section{Electrochemical Growth of Metal Nanowire Inside Silica-mesochannel}

The general scheme of the template-electrodeposition using a mesoporous silica film is shown in Fig. 1. A mesoporous silica film has been commonly prepared by a simple spin- or dip-coating a precursor solution containing silicate and surfactant on an electrode substrate. ${ }^{21,27-29)}$ Conductive glass substrates such as ITO or FTO seem to be suitable for the electrode substrate because of strong adhesion of mesoporous silica film onto the substrate during following calcination and electrodeposition processes. $^{28)}$ After the film coating and calcination to remove template surfactants, the mesoporous silica film has been used as the hard template of a metal nanowire assembly. Wang et $a l^{21)}$ demonstrated the template-elec- trodeposition using the mesoporous silica film at first. In their study, Pd nanowires were grown inside silicamesochannels with two-dimensional (2D) hexagonal alignment by a galvanostatic electroplating, and the mesoporous silica film as the template was removed by submerging the sample in a $2 \% \mathrm{HF}$ solution. After the template removal, the alignment of $\mathrm{Pd}$ nanowires grown inside the silica-mesochannels was almost retained. The diameters of $\mathrm{Pd}$ nanowires ranged from 4 to $8 \mathrm{~nm}$ with an average diameter of $7 \mathrm{~nm}$, which corresponded to the pore diameters of the silica template $(4.7$ to $8.9 \mathrm{~nm})$. In addition, the Pd nanowire assembly showed swirling mesostructure that was shown in the mesoporous silica template. From these results, potential ability of mesoporous silica film as the hard-template of a metal nanowire was concluded. Until now, similar templateelectrodeposition was carried out to fabricate $\mathrm{Pt}$ nanowire assembly with an inverse double-gyroid mesostructure ${ }^{29)}$ and Co nanowire assembly with $2 \mathrm{D}$ hexagonal and 3D cubic mesostructure. ${ }^{27)}$

Mesoporous silica films, which are formed on an electrode by spin- or dip-coating method, have silicamesochannels oriented parallel to an electrode surface. Hence, the use of the mesoporous silica film for the template-electrodeposition results in a metal nanowire assembly with parallel orientation. In contrast, to fabricate metal nanowire assembly standing on an electrode, it is required to form a mesoporous silica film with silicamesochannels oriented perpendicular to an electrode surface. For that purpose, a hybrid mesoporous membrane (HMM) has been paid attention in the template-electrodeposition study.

The HMM is composed of a surfactant-templated mesoporous silica and a porous anodic alumina (PAA) membrane (Fig. 2). ${ }^{30-33)}$ The PAA membrane has a packed array of columnar alumina pores oriented perpendicularly to the membrane surface. When surfactanttemplated mesoporous silica is formed inside the alumina pores, self-organization of silica-mesochannels oriented along the columnar alumina wall takes place. Figure 3 shows typical transmission electron microscopy (TEM) images of HMM with different structures of silicamesochannels; 1 dimensional (1D)-tubular silicamesochannels and silica-mesochannels with circular or stacked-doughnuts structure. As shown in Fig. 4, growth of metal nanowires within the HMM allows formation of a metal nanowire assembly standing on an electrode.
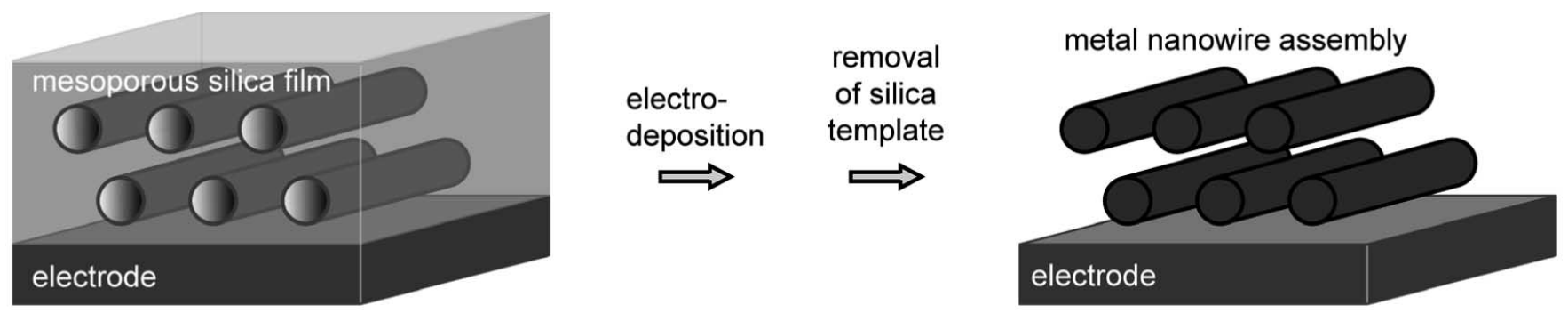

Fig. 1 Scheme of template-electrodeposition of metal nanowire assembly by using mesoporous silica film with 2D hexagonal mesochannel alignment. 


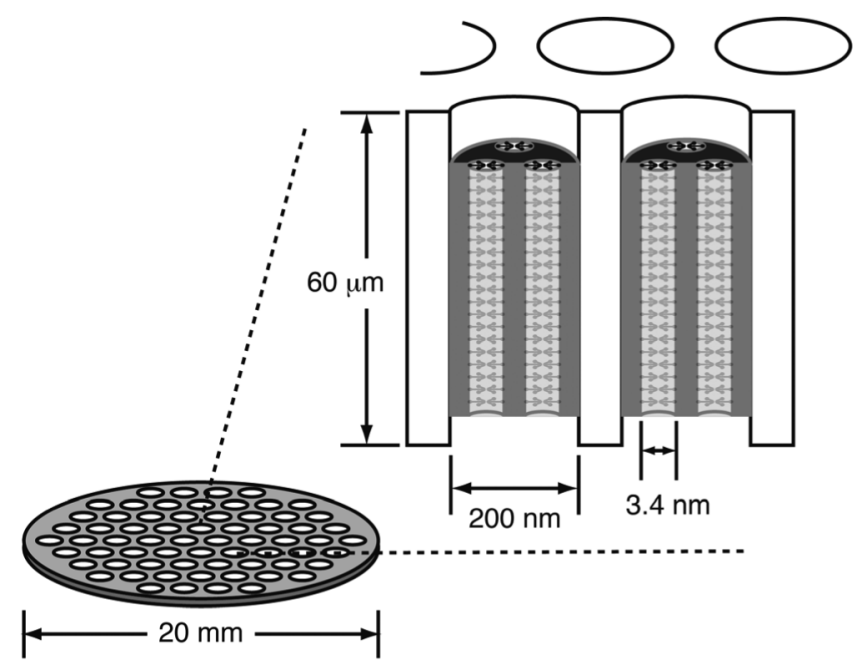

Fig. 2 Scheme of a hybrid mesoporous membrane (HMM) with $1 \mathrm{D}$ tubular silica-mesochannel structure.

(a) 1D tubular mesochannel structure

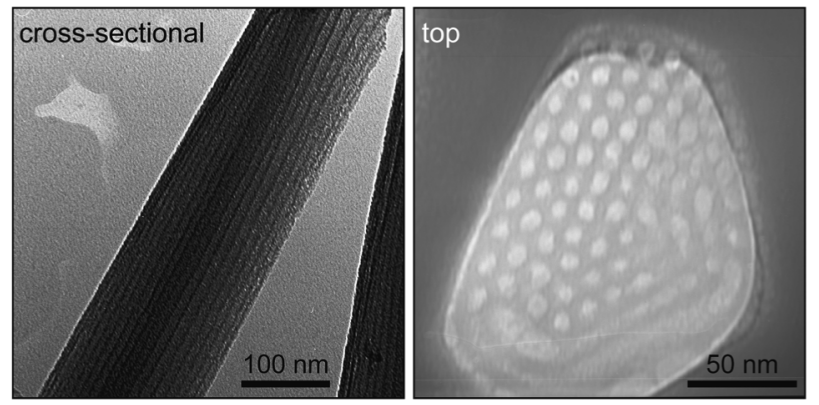

(b) stacked-doughnut mesochannel structure

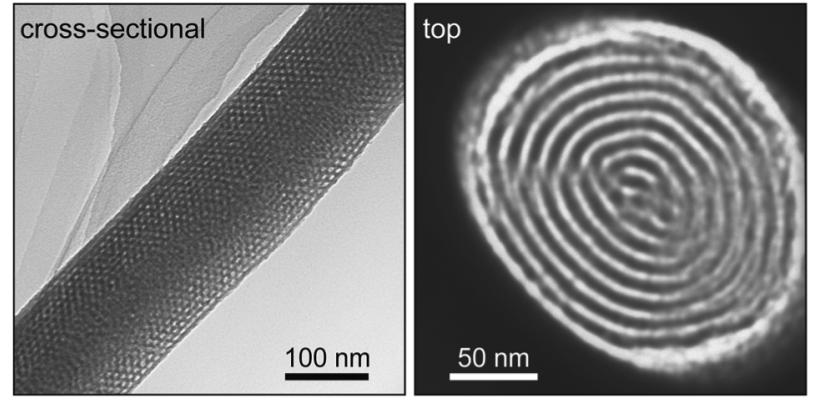

Fig. 3 TEM images of mesoporous silica formed inside the columnar alumina pores: (a) mesoporous silica with 1D tubular mesochannel structure and (b) mesoporous silica with stacked-doughnut mesochannel structure.

Figure 5 (a) shows typical metal nanowire assembly fabricated by using HMM with $1 \mathrm{D}$ tubular silicamesochannels (channel diameter $=3.4 \mathrm{~nm}$ ). ${ }^{34}$ ) In this fabrication, a carbon film was deposited on one side of the HMM by carbon evaporation and was used as a cathode in an electrochemical cell to electroplate metal nanowires inside the silica-mesochannels by conventional DC plating at room temperature. In the $\mathrm{CV}$ curve of a $24 \mathrm{mM}$ $\mathrm{HAuCl}_{4}$ aqueous solution containing $0.5 \mathrm{M} \mathrm{KCl}$, a reduction peak appeared at a potential of $-0.18 \mathrm{~V}$ vs. $\mathrm{Ag} / \mathrm{AgCl}$ (Fig. 6). This potential is close to the reduction potential of $\mathrm{AuCl}_{4}^{-}$on a bare glassy carbon electrode (GC), indicat- (a) PAA membrane

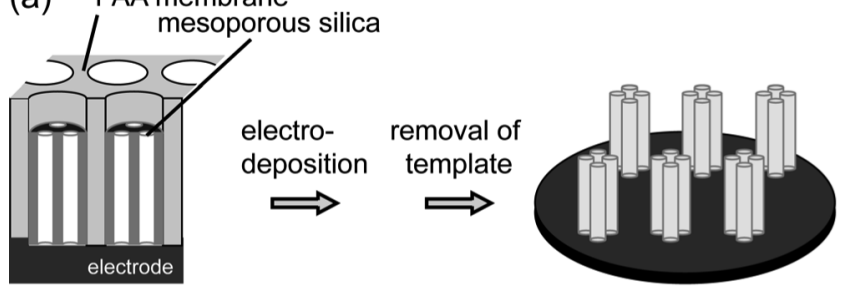

(b)

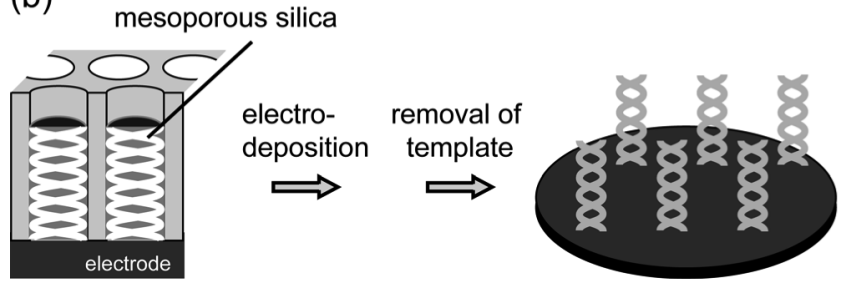

Fig. 4 Schemes of template-electrodeposition of metal nanowire assembly standing on a electrode by using HMMs possessing mesoporous silica (a) with 1D tubular mesochannel structure and (b) with stacked-doughnut mesochannel structure.
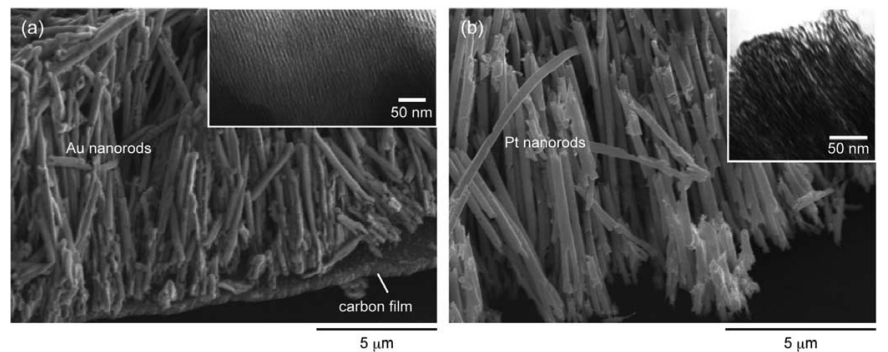

Fig. 5 SEM images of (a) Au nanorods and (b) Pt nanorods standing on the carbon film electrode. Au and Pt nanorods are composed of $1 \mathrm{D}$ nanowire assembly oriented along long axes of the nanorod as shown in insets (TEM images).

ing that a carbon film on the HMM can indeed work as a conventional carbon electrode like GC. Cathodic electrodeposition of gold into the nanochannels was done at a potential of $-1.0 \mathrm{~V}$ vs. $\mathrm{Ag} \mid \mathrm{AgCl}$ in the $24 \mathrm{mM} \mathrm{HAuCl}_{4}$ aqueous solution. After electrodeposition, both alumina and silica matrices were chemically etched, and resulting gold nanostructures were observed by a scanning electron microscopy (SEM) and a transmission electron microscopy (TEM). As shown in Fig. 5 (a), Au nanorods were standing on the carbon film. The local structure of the $\mathrm{Au}$ nanorods were assembly of gold nanowires oriented perpendicularly to the surface of the carbon film, and their diameter was around 3 to $5 \mathrm{~nm}$, corresponding to the average diameter of the silica-mesochannel (3.4 $\mathrm{nm}$ ) within the HMM. Similar nanowire assembly could be also obtained for the template-electrodeposition in 24 $\mathrm{mM} \mathrm{H} \mathrm{H}_{2} \mathrm{PtCl}_{6}$ aqueous solution containing $0.5 \mathrm{M} \mathrm{KCl}$ as shown in Fig. 5 (b). These SEM and TEM images of metal nanowire assemblies indicate that the HMM can be available to fabricate a matal nanorod composed of $1 \mathrm{D}$ metal nanowires with standing orientation. 

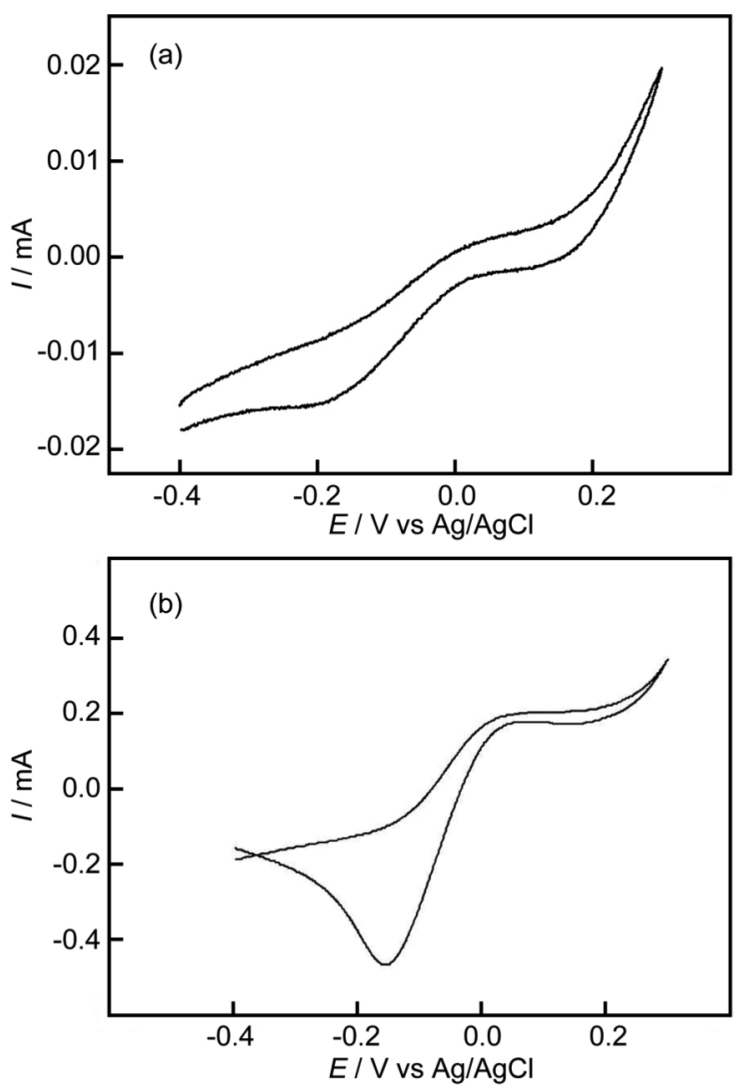

Fig. $6 \mathrm{CV}$ curves obtained by using (a) HMM with a carbon film and (b) a bare glassy carbon electrode ( $\phi: 3$ $\mathrm{mm}$ ) as working electrode, respectively. The aqueous solution contained $24 \mathrm{mM} \mathrm{HAuCl}_{4}$ and $0.5 \mathrm{M} \mathrm{KCl}$.

A HMM with stacked-doughnut silica-mesochannel structure can be used for the template-electrodeposition of helical metal nanowire assembly as schematically shown in Fig. 4 (b). Figure 7 shows typical SEM image of $\mathrm{Ag}$ nanorods grown within the HMM with stackeddoughnut silica-mesochannel structure (see Fig. 3 (b)). These Ag nanowires were electrodeposited under potential cycles between $0 \mathrm{~V}$ and $-2.0 \mathrm{~V}$ vs. $\mathrm{Pt}$ in $0.05 \mathrm{M}$ $\mathrm{AgNO}_{3}$ aqueous solution containing $0.5 \mathrm{M} \mathrm{H}_{3} \mathrm{BO}_{3}$. On the basis of Stucky's reports, ${ }^{35,36)}$ it can be inferred that the individual $\mathrm{Ag}$ nanorods shown in Fig. 7 are helical $\mathrm{Ag}$ nanowire assembly standing on an electrode.

As has been described in this chapter, various metal nanowire assemblies are grown within the HMM. The electrodeposition of metal nanowires within the HMM allows a fabrication of a metal nanowire assembly standing on an electrode surface. The standing orientation is difficult to obtain by other fabrication methods, such as electron-beam lithography, and various template- and templateless-growth. Therefore, the HMM is one of powerful candidate for a nanofabricator of hierarchical and/or well-ordered metal nanowire assembly on an electrode surface.

\section{Construction of Triple Phase Boundary in Surfactant-templated Mesoporous Carbon}

Triple phase boundary, where the catalyst metal, gas phase reagent, and polymer electrolyte (ionomer) are in

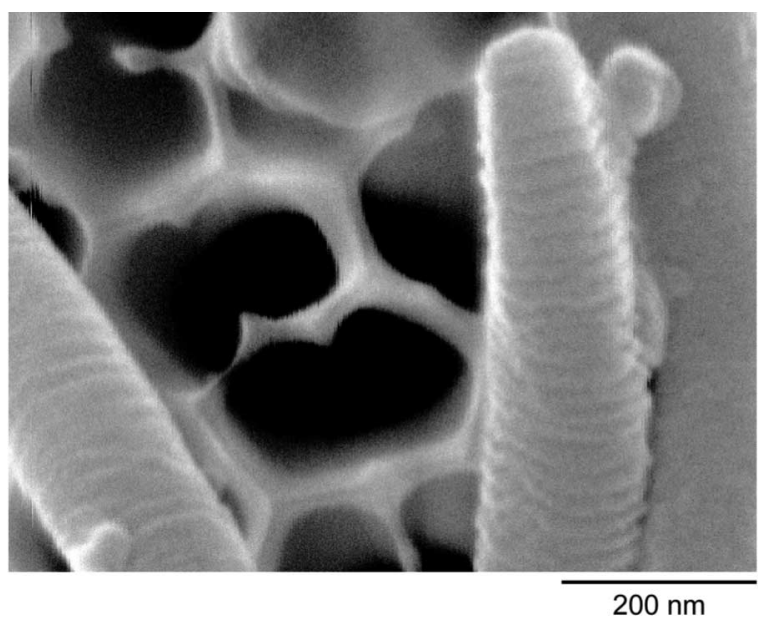

Fig. 7 SEM image of Ag nanorods composed of helical Ag nanowire assembly. In this SEM observation, Ag nanorods, which were removed from the electrode, were collected on a PAA membrane.

close proximity, is well known as reactive sites in gas-diffusion electrodes, such as catalyst layers in PEFC. ${ }^{25)}$ Recently, it has been pointed out that the geometrical arrangement of perfluorosulfonic acid polymer (PFSA), which is the typically used ionomer in PEFC, governs the performance of the catalyst layer, since the electrochemically active surface area can be determined by the contact between catalyst metals and PFSAs thin film. Especially, the catalyst metal is deposited as nanoparticles with 2-5 nm diameters on carbon support and, then, the interaction between PFSAs and the carbon support surface affects the resulting arrangement of PFSAs. ${ }^{37}$ The methodologies to prepare the mixture of catalysts and PFSAs, and to form the catalyst layers, are also important factors. ${ }^{38)}$ From these considerations, various factors can contribute to the loss in the activity of the catalyst layers and the patch treatments seem not to solve the fundamental problems. The bottom-up approach basing on the size-defined materials has been promising and can be applicable to construct the wellunderstood model catalysts.

We have selected surfactant-templated MC with 3D mesopores of $c a .10 \mathrm{~nm}$ diameter to construct the triple phase boundary in the mesopores, ${ }^{22,23)}$ expecting the coexistence of both $\mathrm{Pt}$ nanoparticles with $1-2 \mathrm{~nm}$ diameter and rod-like PFSAs with $1.5-2.5 \mathrm{~nm}$ radius. ${ }^{39-42)}$ Advantages expected for the usage of MC support as compared with conventional $\mathrm{Pt} /$ carbon black (CB) catalyst are as follows: (1) rigid contact between $\mathrm{Pt}$ nanoparticles and PFSAs in mesochannels, (2) stabilization of $\mathrm{Pt}$ nanoparticles in hydrophobic carbon nanochannels, (3) valid exposure of $\mathrm{Pt}$ nanoparticles without burial in thin carbon mesochannel walls, (4) rapid water drain using hydrophobic 3D mesochannels. On the other hand, a disadvantage is expected for the mass transfer in the mesochannels, but this problem can be recovered by tuning morphology and/or thickness of macroscopic catalyst layer.

MC was synthesized through the self-organization of a 

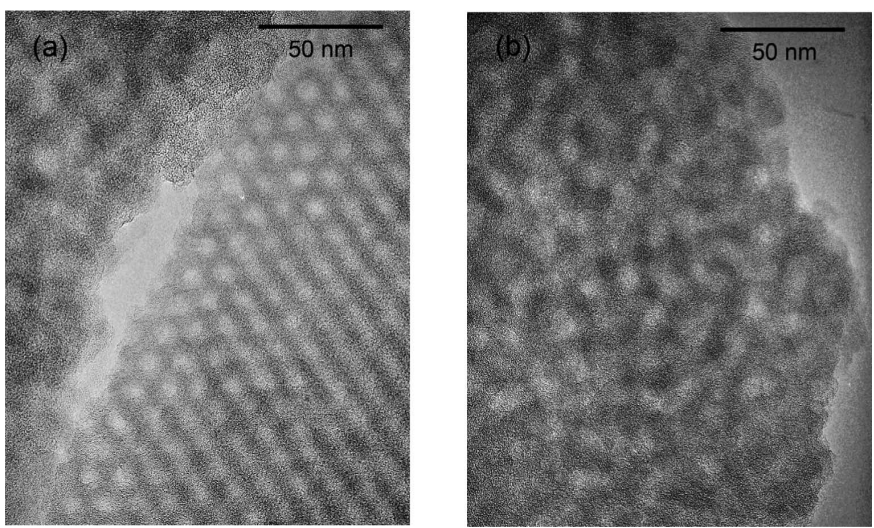

Fig. 8 TEM images of (a) hexagonally ordered and (b) randomly oriented angles of $\mathrm{MC}$ mesopores.

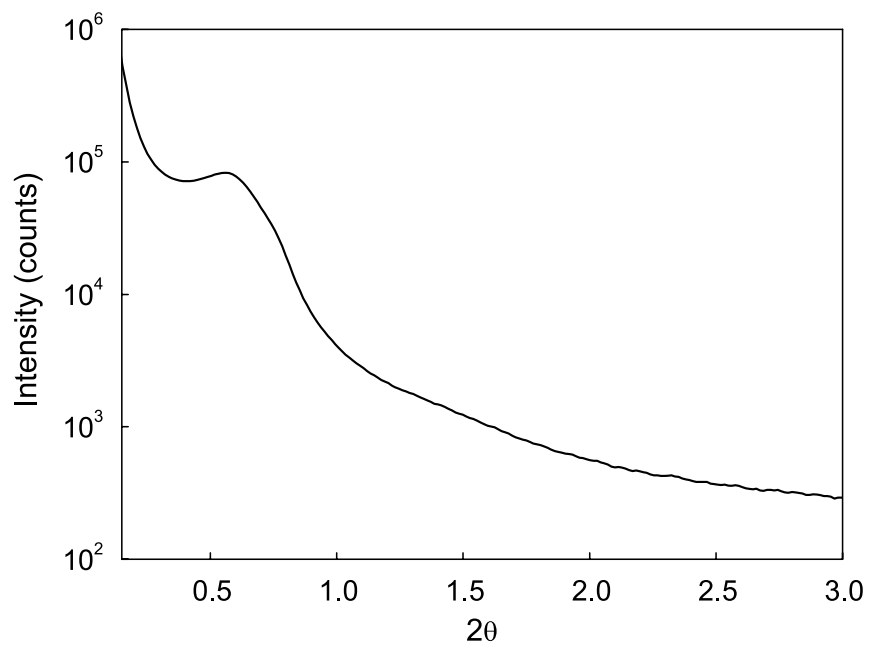

Fig. 9 SAXS pattern of MC powder.

surfactant (Pluronic ${ }^{\circledR}$ F127) and carbon precursors (resorcinol and formaldehyde). MC prepared by the carbonization at $800^{\circ} \mathrm{C}$ in the inert atmosphere was used as standard materials. Details of the MC preparation are described elsewhere. TEM observation gave two different types of photographs. Figure 8 (a) shows a hexagonally ordered pore structure with pore diameter of 7-8 $\mathrm{nm}$. In the other photo (Fig. 8 (b)), pores appear randomly oriented. However, through further observation by changing angles of sample stage from $+58^{\circ}$ to $-68^{\circ}$, pores coming out as randomly oriented have started showing hexagonally ordered at certain angles. That means, hexagonally ordered structure spreads out three dimensionally like a structure of sponge. This ordered pore structure was also expected by the data obtained from SAXS with a broad peak a $2 \theta=1.5^{\circ}(\mathrm{Cu} \mathrm{K} \alpha)$ shown in Fig. 9. The specific surface area and average pore diameter calculated from the nitrogen sorption isotherm by BET method and BJH method were around $600 \mathrm{~m}^{2} / \mathrm{g}$ and 7-8 nm, respectively. ${ }^{22)}$

Pt deposition was carried out by impregnant method. By changing the Pt precursors and solvents, we could control the approximate morphology of Pt deposits. ${ }^{22,43}$ For example, the combination of $\mathrm{Pt}$ (acac) $)_{2}$ and dichloromethane resulted in the homogeneous $\mathrm{Pt}$

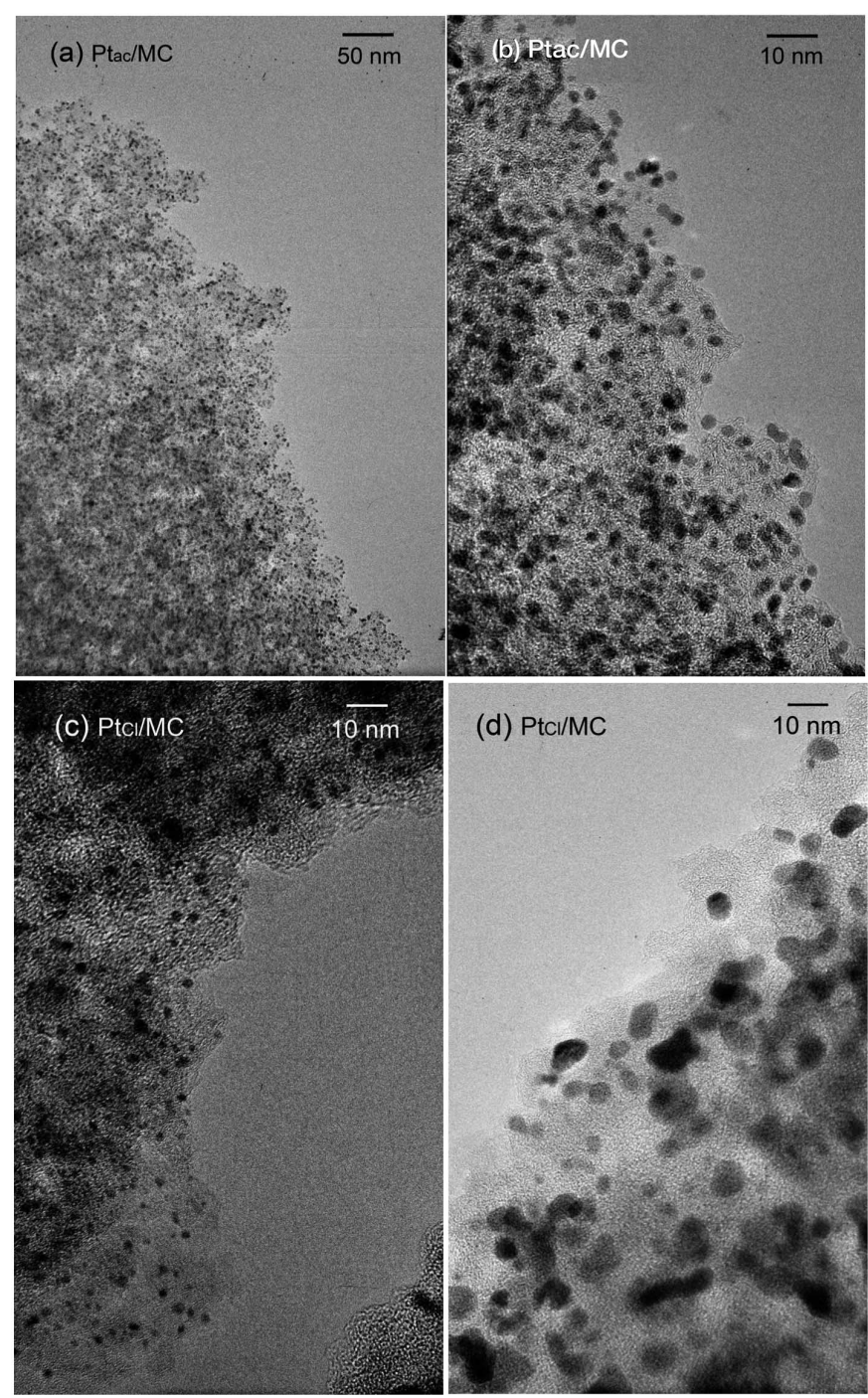

Fig. 10 TEM images of $\mathrm{Pt}_{\mathrm{ac}} / \mathrm{MC}((\mathrm{a})$ and (b) with different magnification) and $\mathrm{Pt}_{\mathrm{Cl}} / \mathrm{MC}((\mathrm{c})$ and (d) with different location).

nanoparticles $\left(\mathrm{Pt}_{\mathrm{ac}} / \mathrm{MC}\right)$ with a diameter of $c a .2 \mathrm{~nm}$, as shown in Fig. 10 (a) and (b). On the other hand, the combination of $\mathrm{H}_{2} \mathrm{PtCl}_{6}$ and acetone resulted in $\mathrm{Pt}$ nanoparticles deposition $\left(\mathrm{Pt}_{\mathrm{Cl}} / \mathrm{MC}\right)$ with broad distributed diameters, as shown in Fig. 10 (c) and (d). From the reproducibility and the homogeneousness, $\mathrm{Pt}_{\mathrm{ac}} / \mathrm{MC}$ catalyst is used to investigate the electrochemical behaviors specific to mesoporous structures, although the $\mathrm{Pt}_{\mathrm{Cl}} / \mathrm{MC}$ showed more superior performance than that at $\mathrm{Pt}_{\mathrm{ac}} / \mathrm{MC}$, as shown later.

Evaluation of the electrocatalytic activity of prepared catalysts for the cathode reaction (oxygen reduction reaction: ORR) was performed using rotating disk electrode (RDE) with a hanging-meniscus configuration in $\mathrm{O}_{2}$ saturated $0.1 \mathrm{M} \mathrm{HClO}_{4}$ solution (Fig. 11). Surface density of $\mathrm{Pt}$ was kept to be $14 \mu \mathrm{g} \mathrm{cm}^{-2}$ for all the samples. $\mathrm{Pt}_{\mathrm{ac}} / \mathrm{MC}$ catalysts dispersed in 2-propanol was cast on the mirror-finished carbon rod electrode with a diameter of $5 \mathrm{~mm}$ and $0.05 \mathrm{wt} \%$ Nafion (the most popular PFSAs) solution was cast, dried, and heated in air at $120{ }^{\circ} \mathrm{C}$ for 1 h. When the Nafion was diluted by EtOH and $\mathrm{H}_{2} \mathrm{O}(6: 4)$, 


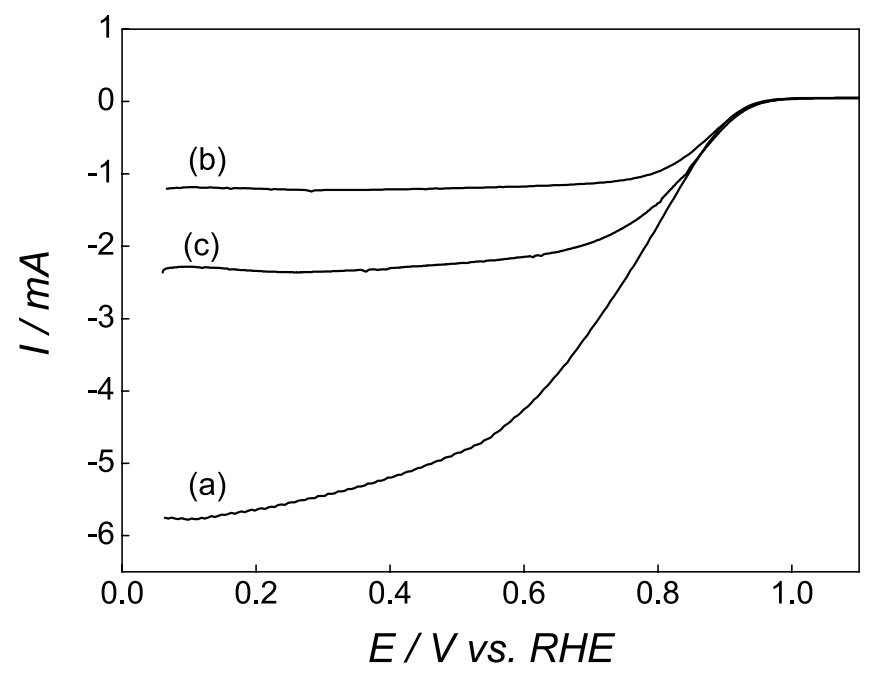

Fig. 11 Positive going linear sweep voltammograms of $\mathrm{Pt}_{\mathrm{ac}} / \mathrm{MC}$ in $\mathrm{O}_{2}$ saturated $0.1 \mathrm{M} \mathrm{HClO}_{4}$ solution at the rotating speed of $1600 \mathrm{rpm}$ and the sweep rate of $20 \mathrm{mV} / \mathrm{s}$. Catalysts and position of electrode against the electrolyte solution were (a) $\mathrm{Pt}_{\mathrm{ac}} / \mathrm{MC}$ with Nafion ${ }^{\circledR} / 1,1,1,3,3,3$-hexafluoro2-propanol and hanging meniscus to the solution, (b) $\mathrm{Pt}_{\mathrm{ac}} / \mathrm{MC}$ with Nafion ${ }^{\circledR} /$ water-ethanol and hanging meniscus to the solution, and (c) $\mathrm{Pt}_{\mathrm{ac}} / \mathrm{MC}$ with $\mathrm{Nafion}^{\circledR} / 1,1,3,3,3$ hexafluoro-2-propanol and in the solution, respectively.

the ORR current at $\mathrm{Pt}_{\mathrm{ac}} / \mathrm{MC}$ thin film $\mathrm{RDE}$ showed plateau depending on the electrode rotational speed and the values obtained at $1600 \mathrm{rpm}$ was $6.0 \mathrm{~mA} \mathrm{~cm}-2$, which was exactly the same as the diffusion limiting current values observed at $\mathrm{Pt} / \mathrm{CB}$ thin film $\mathrm{RDE}$. On the other hand, much larger ORR current independent on the electrode rotational speed were observed at the electrodes prepared by Nafion solutions diluted by EtOH or 1,1,1,3,3,3-hexafluoro-2-propanol (HFP). ${ }^{44)}$ ORR current exceeding the diffusion-limiting current was reported in several cases, where the reaction sites are three-dimensionally distributed and the gaseous oxygen can be transferred directly from gas-phase in the thin film formed on RDE. In the present case, the penetration of PFSAs inside the Pt deposited mesochannels caused the formation of the three-dimensionally distributed reaction sites and the hanging-meniscus configuration promoted the gaseous $\mathrm{O}_{2}$ transfer via PFSAs inside the mesochannels. When the PFSAs was cast from the solution containing $\mathrm{H}_{2} \mathrm{O}$, the slow drying of the solvent caused large cluster formation of PFSAs at the $\mathrm{Pt}_{\mathrm{ac}} / \mathrm{MC}$ surfaces, preventing the penetration of PFSA inside the mesochannels. Since the proton transfer inside the mesochannels were suppressed by the absence of PFSAs, Pt nanoparticles inside the mesochannels did not work as the ORR sites. Thus, only the Pt nanoparticles outside the nanochannels contributed to the ORR current and the diffusion-limiting current corresponding to the twodimensionally distributed reaction sites was observed. On the other hand, PFSAs can easily penetrate inside the hydrophobic mesochannnels, when the EtOH or HFP was used to dilute PFSAs. The penetration depth may depend on the hydrophobicity of diluted solvent or the

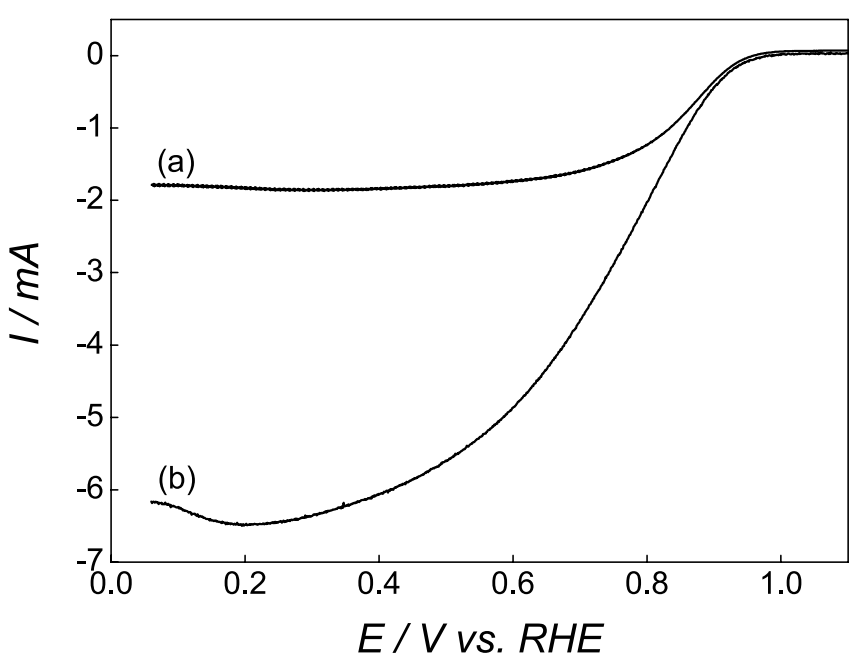

Fig. 12 Linear sweep voltammograms of (a) $\mathrm{Pt}_{\mathrm{ac}} / \mathrm{MC}$, and (b) $\mathrm{Pt}_{\mathrm{Cl}} / \mathrm{MC}$ under $\mathrm{O}_{2}$ saturated condition at the rotating speed of $1600 \mathrm{rpm}$ and the sweep rate of $20 \mathrm{mV} / \mathrm{s}$.

dispersed size of PFSAs in the solution. It is also possible that the intermolecular interaction between perfluorocarbon chains in both the PFSAs and HFP caused different dispersion shape and size, which can promote the penetration inside the mesochannels. Although the reason cannot be clarified, $\mathrm{Pt}_{\mathrm{ac}} / \mathrm{MC}$ thin layer $\mathrm{RDE}$ prepared by HFP-diluted PFSAs showed better ORR performance than that by EtOH-diluted ones. The tendency of ORR performances depending on the PFSAs-diluting solvents were the same at $\mathrm{Pt}_{\mathrm{Cl}} / \mathrm{MC}$ thin layer electrodes. In addition, solvent dependency of the penetration depth of PFSAs inside the mesochannels was recently proved by depth profiling at free-standing carbon films with mesopores. ${ }^{23,45)}$

As shown in Fig. 12, the ORR performance at $\mathrm{Pt}_{\mathrm{Cl}} / \mathrm{MC}$ always exceeds that at $\mathrm{Pt}_{\mathrm{ac}} / \mathrm{MC}$, when all other condition except for the impregnant and reduction conditions for Pt deposition are the same, although the homogeneousness of $\mathrm{Pt}$ deposits seems well-defined at $\mathrm{Pt}_{\mathrm{ac}} / \mathrm{MC}$, as has been recognized from the TEM images (Fig. 10). Since the higher ORR performance at $\mathrm{Pt}_{\mathrm{cl}} / \mathrm{MC}$ than $\mathrm{Pt}_{\mathrm{ac}} / \mathrm{MC}$ can be caused by the morphology of Pt deposits inside the mesochannels, the sliced samples with $50 \mathrm{~nm}$ thickness were prepared by microtome and were observed by dark-field scanning TEM (Figs. 13 and 14). In the dark-field STEM images, Pt deposits were shown as bright spots. The cross section of whole particle of $\mathrm{Pt}_{\mathrm{Cl}} / \mathrm{MC}$ is shown in Fig. 13 (a). The edge of the image indicates the surface of a $\mathrm{Pt}_{\mathrm{Cl}} / \mathrm{MC}$ particle, and the middle part of the image shows the inside of a $\mathrm{Pt}_{\mathrm{Cl}} / \mathrm{MC}$ particle. The area pointed by arrow in Fig. 13 (a) was observed by higher magnification. In the higher magnification (Fig. 13 (b)), aggregation of large $\mathrm{Pt}$ particles (white spots) is observed in the surface region of the $\mathrm{Pt}_{\mathrm{Cl}} / \mathrm{MC}$ particle, but if we look inside the particle, the condition is totally different. A number of 1-nm or smaller Pt particles are well dispersed along the wall of mesochannels perpendicular to the cross section, but also on the cross sectional surface. This is because that 

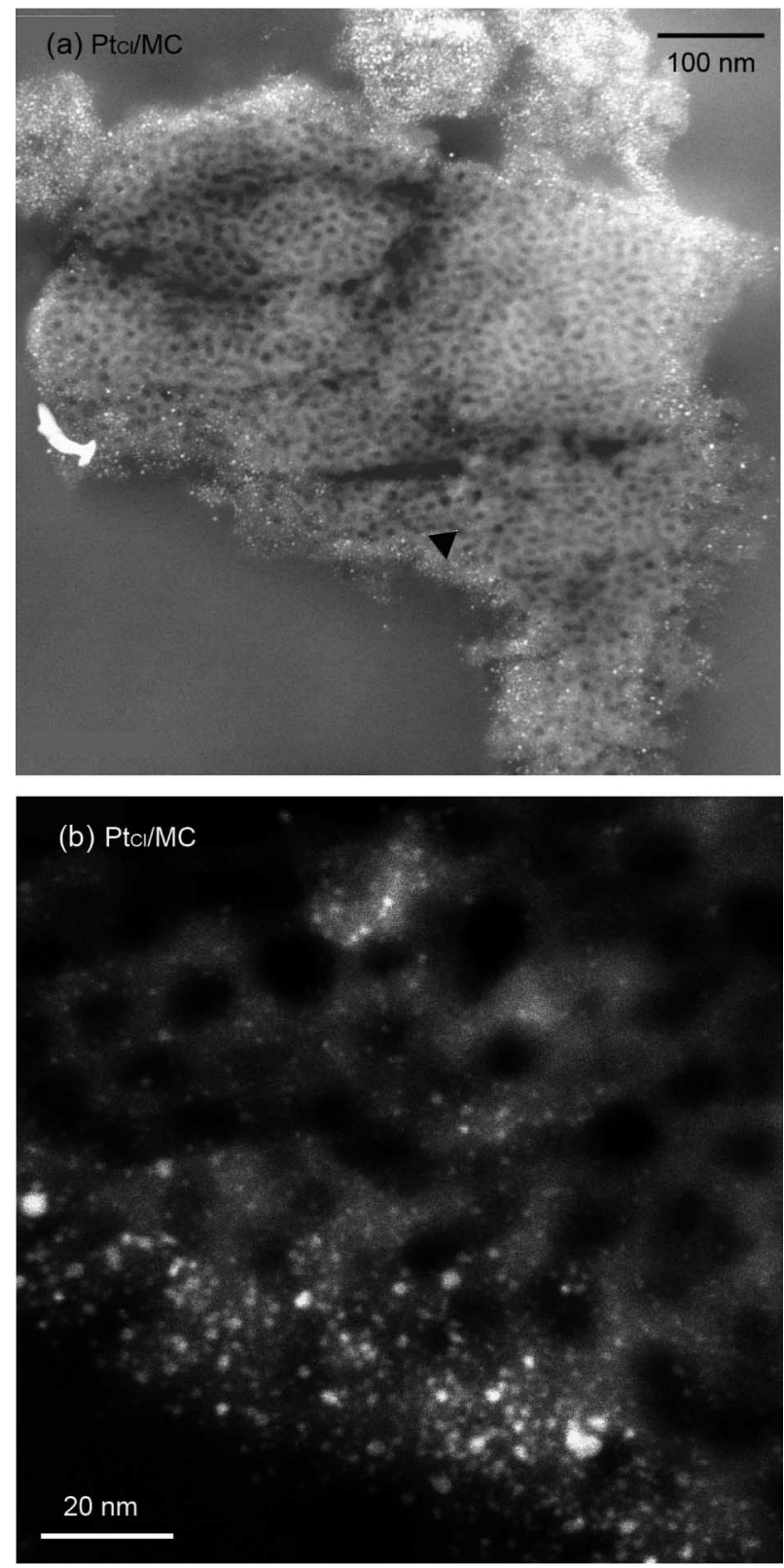

Fig. 13 STEM dark field images of $\mathrm{Pt}_{\mathrm{Cl}} / \mathrm{MC}$ : (a) low and (b) high magnifications. Pt nanoparticles appear as white spots.

mesochannels are three dimensionally ordered, and mesochannels parallel to the cross sectional surface also exist. Those pores are sliced, and Pt staying within the pores now appears on the surface in this figure. Similarly, the cross section of $\mathrm{Pt}_{\mathrm{ac}} / \mathrm{MC}$ was observed by STEM. As seen in Fig. 14, $2 \mathrm{~nm}$ sized Pt particles are well dispersed also inside the mesochannels. Particle size distributions of both $\mathrm{Pt}_{\mathrm{Cl}} / \mathrm{MC}$ and $\mathrm{Pt}_{\mathrm{ac}} / \mathrm{MC}$ analyzed from Figs. 13 (b) and 14 (b) are summarized in Fig. 15. It is clear that smaller $\mathrm{Pt}$ particles exist in $\mathrm{Pt}_{\mathrm{Cl}} / \mathrm{MC}$ than $\mathrm{Pt}_{\mathrm{ac}} / \mathrm{MC}$. Therefore, $\mathrm{Pt}_{\mathrm{Cl}} / \mathrm{MC}$ with much smaller $\mathrm{Pt}$ particles inside the pores has shown better performance than $\mathrm{Pt}_{\mathrm{ac}} / \mathrm{MC}$ with $2 \mathrm{~nm}$ sized Pt particles. It should be noted that smaller Pt particles are preferred for catalytic reaction due to their higher surface area, but sintering is always a problem. However, even very small particles (1
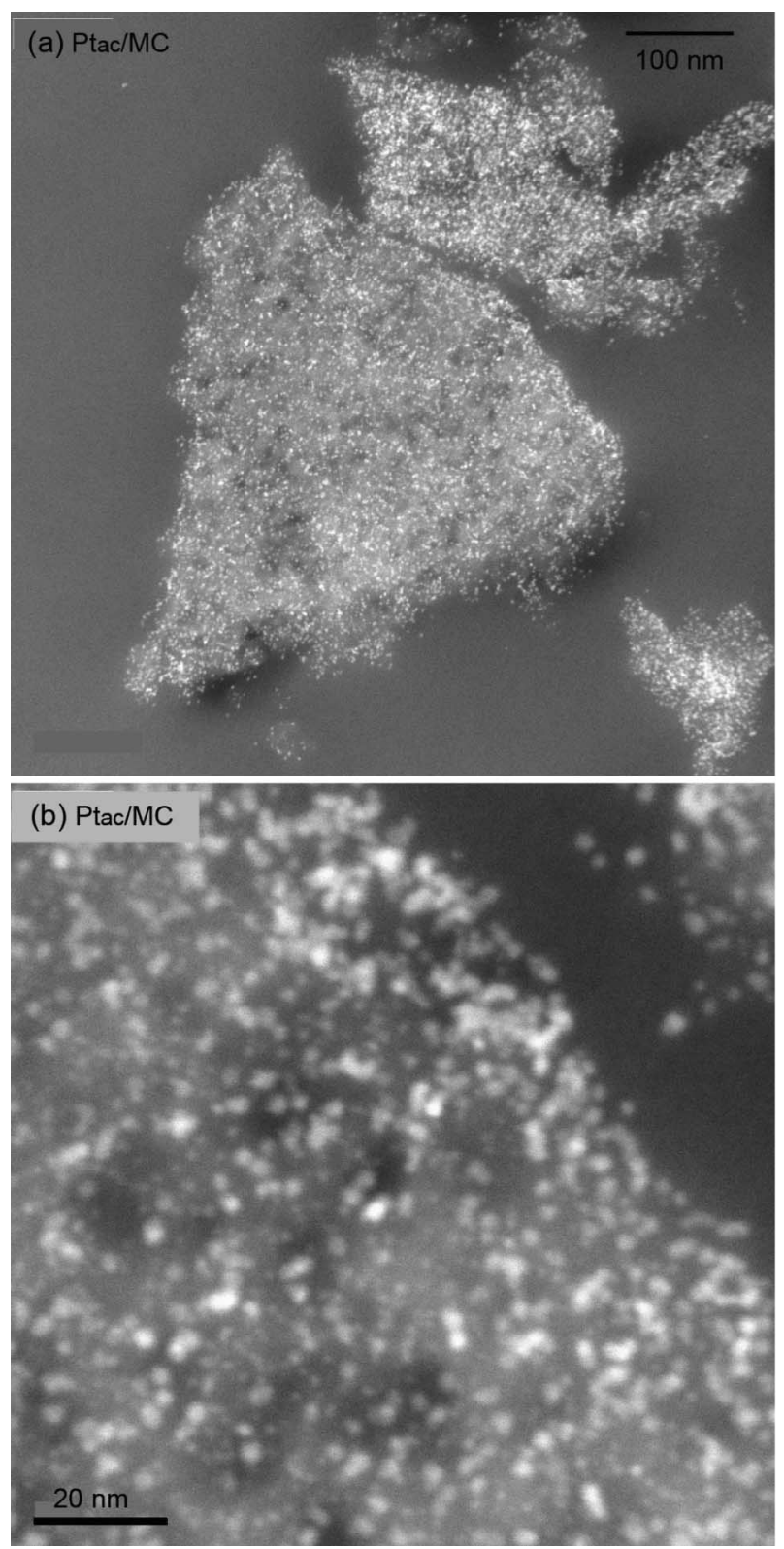

Fig. 14 STEM dark field images of $\mathrm{Pt}_{\mathrm{ac}} / \mathrm{MC}$ : (a) low and (b) high magnifications. Pt nanoparticles appear as white spots.

$\mathrm{nm}$ and smaller) can be stabilized if they are encapsulated inside mesochannels, and so small Pt particles can still keep high reactivity. ${ }^{43)}$ Direct observation method has lead to an important understanding of reactivity in nanospace.

The durability of $\mathrm{Pt}_{\mathrm{Cl}} / \mathrm{MC}$ catalyst was preliminary tested by potential cycling between $+0.6 \mathrm{~V}$ and $+1.1 \mathrm{~V}$ vs. RHE in air-saturated $0.1 \mathrm{M} \mathrm{HClO}_{4}$ solution. Figure 16 compares the ORR mass activities at $+0.85 \mathrm{~V}$ vs. RHE of $\mathrm{Pt}_{\mathrm{Cl}} / \mathrm{MC}$ and commercially available $\mathrm{Pt} / \mathrm{CB}$ (Vulcan $\mathrm{XC72)}$ before and after the 20000 potential cycling, respectively. Although $25 \%$ loss of the ORR mass activity was observed at the $\mathrm{Pt} / \mathrm{CB}$ electrode, the activity loss at $\mathrm{Pt}_{\mathrm{Cl}} / \mathrm{MC}$ was only $12 \%$. Recently, it has been well understood that the degradation of Pt catalysts at cathode catalyst layer is due to the loss of the electrochemically active surface area as a result of the particle 

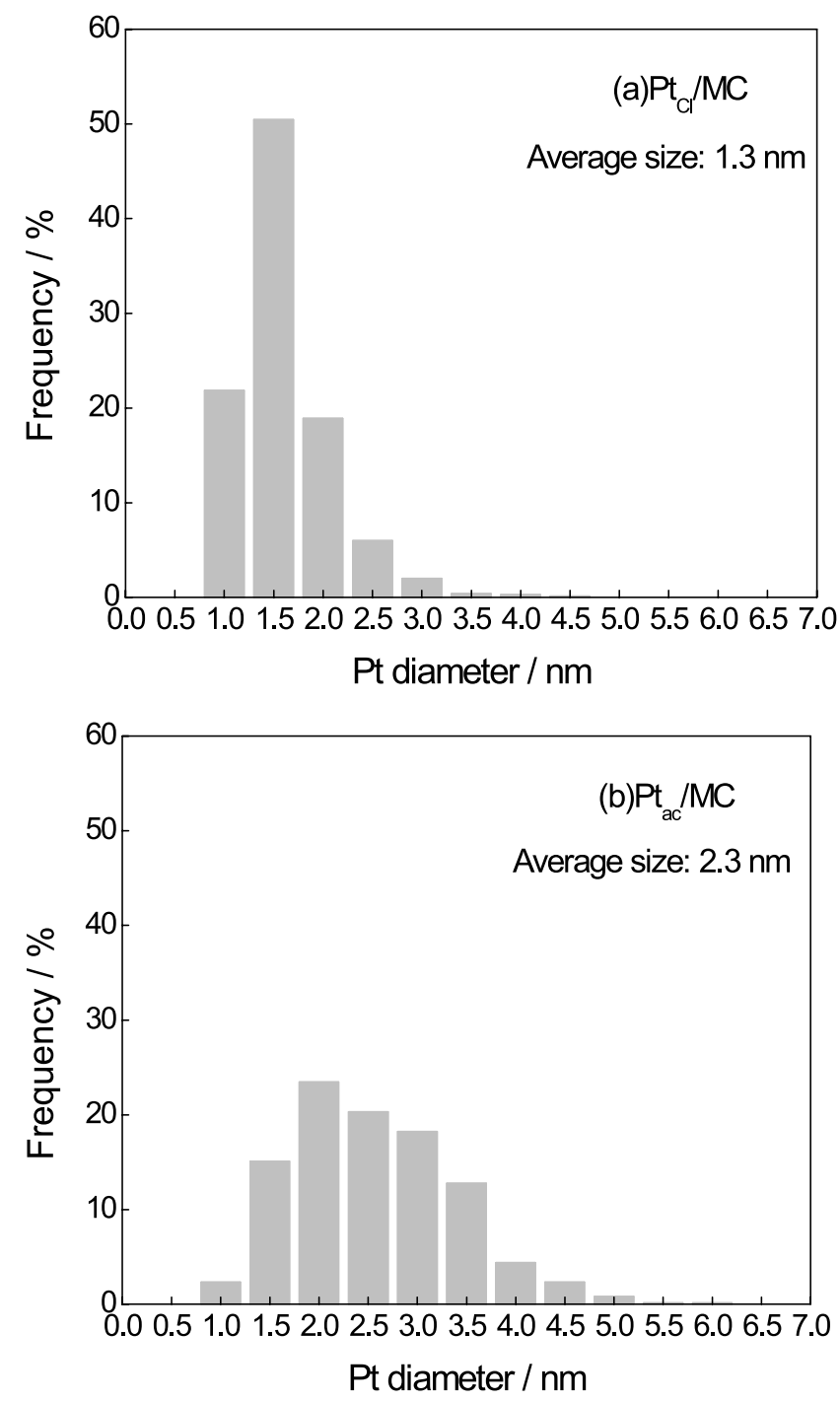

Fig. $15 \mathrm{Pt}$ size distributions inside mesopores of Ptdeposited MC catalysts based on (a) Fig. 13b and (b) Fig. $14 \mathrm{~b}$.

growth at Pt nanoparticles caused by dissolution/redeposition cycles at relatively positive potential region (Growth via modified Ostwald Ripening). ${ }^{46)}$ The dissolution of $\mathrm{Pt}$ in acidic solution is well known to occur in the following scheme ${ }^{47)}$ :

$$
\begin{gathered}
\mathrm{Pt}_{(\mathrm{s})}+\mathrm{H}_{2} \mathrm{O} \longleftrightarrow \mathrm{PtO}_{(\mathrm{s})}+2 \mathrm{H}^{+}{ }_{(*)}+2 \mathrm{e}^{-} \\
\mathrm{PtO}_{(\mathrm{s})}+2 \mathrm{H}^{+}{ }_{(*)} \longleftrightarrow \mathrm{Pt}^{2+}{ }_{(*)}+\mathrm{H}_{2} \mathrm{O}
\end{gathered}
$$

where (s) and (*) stand for solid and ionic species present in water or in ionomer phase, respectively. From these schemes, it can be easily understood that the activity of water, $\left[\mathrm{H}_{2} \mathrm{O}\right]$, should be suppressed to inhibit the first step, PtO formation. However, a certain amount of water is required to be supplied to drive ORR. The hydrophobic nature of mesochannels' walls in MC support and PFSAs filling inside the mesochannels are expected to correlatively keep the value of $\left[\mathrm{H}_{2} \mathrm{O}\right]$ as minimum as possible in the mesochannels. Thus, we believe that the degradation of $\mathrm{Pt}$ at $\mathrm{Pt}_{\mathrm{Cl}} / \mathrm{MC}$ catalyst occurs only outside of the mesochannels and the Pt nanoparti-

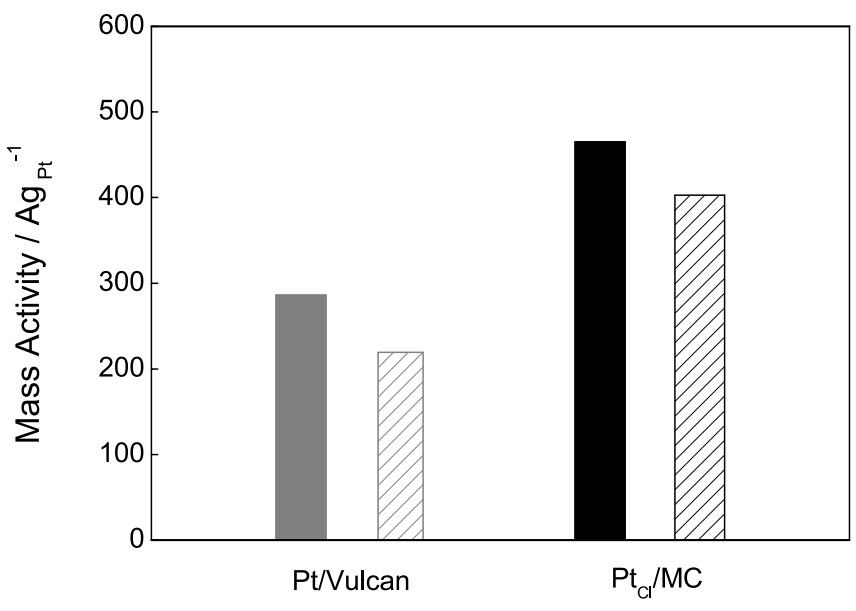

Fig. 16 The results of durability test of the commercially available $\mathrm{Pt} / \mathrm{CB}$ (Vulcan $\mathrm{XC} 72$ ) and $\mathrm{Pt}_{\mathrm{Cl}} / \mathrm{MC}$ catalysts. The mass activity values for ORR at $0.85 \mathrm{~V}$ vs. RHE before (solid bars) and after (striped bars) the 20000 potential cycling between +0.6 and $+1.1 \mathrm{~V}$ vs. RHE are plotted.

cles inside the mesochannels are maintained during potential cycles. Direct observation of Pt nanoparticles inside the mesochannels by dark field STEM before and after durability tests are desired, but the preparation method for the large scale electrode samples, where the triple phase boundary are rigidly constructed inside the mesochannels, have not been established yet. Additionally, we are now trying to prepare $\mathrm{Pt} / \mathrm{MC}$ catalyst with Pt nanoparticles only inside the mesochannels to realize the degradation-free catalyst basing on our concept of the nanoreactor array.

\section{Conclusion}

We have introduced experimental approaches concerning to the nanofabricator and nanoreactor using surfactant-templated mesoporous materials. For the nanofabrication, the construction of HMM realized the ordered nanomaterials standing on an electrode. Relatively complicated nanostructures, such as stacked-nanodoughnut metals, can be prepared homogeneously and accumulatively. This bottom-up technology may be useful to construct hierarchical and/or well-ordered metal nanowire assembly on solid substrate surfaces, where various electrical and optical phenomena, such as anisotropic surface plasmon excitation and single molecular switching, can be induced. For the nanoreactor array, we have succeeded to construct triple phase boundary in relatively large $(\sim 10 \mathrm{~nm})$ mesochannels in surfactant-templated $\mathrm{MC}$ by tuning Pt deposition and introduction of PFSAs. The specific features, such as gaseous material transfer via PFSAs-filled mesochannels and stabilization of Pt subnanoparticles, are found by accumulating experimental results. Furthermore, we have suggested that controlling the activity of water inside the hydrophobic nanospaces becomes one of the novel concepts to suppress the degradation of Pt catalyst in PEFC cathode. However, there are still a lot of subjects to understand the electrochemical and electrocatalytic reaction occurring in 
nanospaces.

\section{Acknowledgement}

This work was partially supported by Fuel Cell Promotion Office of the Agency of Natural Resources and Energy, Ministry of Economy, Trade and Industry (METI) and New Energy, Industrial Technology Development Organization (NEDO). IY and AY also acknowledge KAKENHI (Grant-in-Aid for Scientific Research) on Priority Area "Strong Photon-Molecule Coupling Fields (NO. 470)" from the Ministry of Education, Culture, Sports, Science and Technology (MEXT) of Japan

\section{References}

1) T. Yanagisawa, T. Shimizu, K. Kuroda, and C. Kato, Bull. Chem. Soc. Jpn., 63, 1535 (1990).

2) J. S. Beck, J. C. Vartuli, W. J. Roth, M. E. Leonowicz, C. T. Kresge, K. D. Schmitt, C. T. W. Chu, D. H. Olson, E. W. Sheppard, S. B. McCullen, J. B. Higgins, and J. L. Schlenker, J. Am. Chem. Soc., 114, 10834 (1992).

3) C. T. Kresge, M. E. Leonowicz, W. J. Roth, J. C. Vartuli, and J. S. Beck, Nature, 359, 710 (1992).

4) F. Schuth, Chem. Mater., 13, 3184 (2001).

5) Y. Yamauchi, A. Sugiyama, R. Morimoto, A. Takai, and K. Kuroda, Angew. Chem., Int. Ed., 47, 5371 (2008).

6) S. C. Warren, L. C. Messina, L. S. Slaughter, M. Kamperman, Q. Zhou, S. M. Gruner, F. J. DiSalvo, and U. Wiesner, Science, 320, 1748 (2008).

7) G. S. Attard, P. N. Bartlett, N. R. B. Coleman, J. M. Elliott, J. R. Owen, and J. H. Wang, Science, 278, 838 (1997).

8) K. Landskron and G. A. Ozin, Science, 306, 1529 (2004).

9) C. D. Liang, Z. J. Li, and S. Dai, Angew. Chem., Int. Ed., 47, 3696 (2008).

10) A. Stein, Z. Y. Wang, and M. A. Fierke, Adv. Mater., 21, 265 (2009).

11) A. Vinu, T. Mori, and K. Ariga, Sci. Tech. Adv. Mater., 7, 753 (2006).

12) A. Stein, B. J. Melde, and R. C. Schroden, Adv. Mater., 12, 1403 (2000)

13) R. Liu, Y. Ren, Y. Shi, F. Zhang, L. Zhang, B. Tu, and D. Zhao, Chem. Mater., 20, 1140 (2008).

14) R. L. Liu, Y. F. Shi, Y. Wan, Y. Meng, F. Q. Zhang, D. Gu, Z. X. Chen, B. Tu, and D. Y. Zhao, J. Am. Chem. Soc., 128, 11652 (2006).

15) C. Sanchez, C. Boissiere, D. Grosso, C. Laberty, and L. Nicole, Chem. Mater., 20, 682 (2008).

16) T. J. Barton, L. M. Bull, W. G. Klemperer, D. A. Loy, B. McEnaney, M. Misono, P. A. Monson, G. Pez, G. W. Scherer, J. C. Vartuli, and O. M. Yaghi, Chem. Mater., 11, 2633 (1999).

17) Y. Wan and D. Y. Zhao, Chem. Rev., 107, 2821 (2007).

18) Y. J. Han, J. M. Kim, and G. D. Stucky, Chem. Mater., 12, 2068 (2000).

19) Z. Liu, Y. Sakamoto, T. Ohsuna, K. Hiraga, O. Terasaki, C. H. Ko, H. J. Shin, and R. Ryoo, Angew. Chem., Int. Ed., 39, 3107 (2000).
20) Y. Sakamoto, A. Fukuoka, T. Higuchi, N. Shimomura, S. Inagaki, and M. Ichikawa, J. Phys. Chem. B, 108, 853 (2004).

21) D. H. Wang, W. L. Zhou, B. F. McCaughy, J. E. Hampsey, X. L. Ji, Y. B. Jiang, H. F. Xu, J. K. Tang, R. H. Schmehl, C. O'Connor, C. J. Brinker, and Y. F. Lu, Adv. Mater., 15, 130 (2003).

22) A. Hayashi, H. Notsu, K. Kimijima, J. Miyamoto, and I. Yagi, Electrochim. Acta, 53, 6117 (2007).

23) K. Kimijima, A. Hayashi, and I. Yagi, Chem. Comm., 5809 (2008).

24) L. Carrette, K. A. Friedrich, and U. Stimming, Chem. Phys. Chem, 1, 162 (2000).

25) S. Litster and G. McLean, J. Power Sources, 130, 61 (2004).

26) M. Winter and R. J. Brodd, Chem. Rev., 104, 4245 (2004).

27) H. M. Luo, D. H. Wang, J. B. He, and Y. F. Lu, J. Phys. Chem. B, 109, 1919 (2005).

28) T. Suzuki, H. Miyata, T. Noma, and K. Kuroda, J. Phys. Chem. C, 112, 1831 (2008).

29) V. N. Urade, T. C. Wei, M. P. Tate, J. D. Kowalski, and H. W. Hillhouse, Chem. Mater., 19, 768 (2007).

30) A. Yamaguchi and N. Teramae, Anal. Sci., 24, 25 (2008).

31) W. S. Fu, A. Yamaguchi, H. Kanedaa, and N. Teramae, Chem. Comm., 853 (2008).

32) A. Yamaguchi, H. Kaneda, W. S. Fu, and N. Teramae, Adv. Mater., 20, 1034 (2008).

33) A. Yamaguchi, F. Uejo, T. Yoda, T. Uchida, Y. Tanamura, T. Yamashita, and N. Teramae, Nature Mater., 3, 337 (2004).

34) Y. Chen, A. Yamaguchi, T. Atou, K. Morita, and N. Teramae, Chem. Lett., 35, 1352 (2006).

35) Y. Y. Wu, G. S. Cheng, K. Katsov, S. W. Sides, J. F. Wang, J. Tang, G. H. Fredrickson, M. Moskovits, and G. D. Stucky, Nature Mater., 3, 816 (2004).

36) Y. Y. Wu, T. Livneh, Y. X. Zhang, G. S. Cheng, J. F. Wang, J. Tang, M. Moskovits, and G. D. Stucky, Nano Lett., 4, 2337 (2004).

37) H. A. Gasteiger, S. S. Kocha, B. Sompalli, and F. T. Wagner, Appl. Cat. B, 56, 9 (2005).

38) A. Ignaszak, S. Ye, and E. Gyenge, J. Phys. Chem. C, 113, 298 (2009).

39) P. Aldebert, G. Gebel, B. Loppinet, and N. Nakamura, Polymer, 36, 431 (1995).

40) P. A. Cirkel, T. Okada, and S. Kinugasa, Macromolecules, 32, 531 (1999).

41) B. Loppinet and G. Gebel, Langmuir, 14, 1977 (1998).

42) B. Loppinet, G. Gebel, and C. E. Williams, J. Phys. Chem. $B$, 101, 1884 (1997).

43) A. Hayashi, K. Kimijima, J. Miyamoto, and I. Yagi, Chem. Lett., 38, 346 (2009).

44) A. Hayashi, K. Kimijima, J. Miyamoto, and I. Yagi, J. Phys. Chem. C, 113, 12149 (2009).

45) K. Kimijima, A. Hayashi, and I. Yagi, in preparation.

46) Y. Shao-Horn, W. C. Sheng, S. Chen, P. J. Ferreira, E. F. Holby, and D. Morgan, Top. Catal., 46, 285 (2007).

47) E. Guilminot, A. Corcella, F. Charlot, F. Maillard, and M. Chatenet, J. Electrochem. Soc., 154, B96 (2007). 